\title{
Strain hardening in Fe-16Mn-10Al-0.86C-5Ni high specific strength steel
}

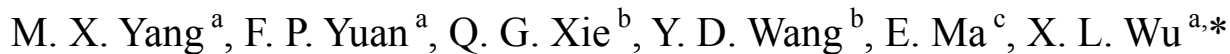

${ }^{a}$ State Key Laboratory of Nonlinear Mechanics, Institute of Mechanics, Chinese Academy of Sciences, 15 Beisihuan West Road, Beijing 100190, China

${ }^{\mathrm{b}}$ School of Materials Science and Engineering, Beijing Institute of Technology, 30 Xueyuan Road, Beijing 100081, China

${ }^{c}$ Department of Materials Science and Engineering, Johns Hopkins University, 3400 North Charles Street, Baltimore, MD 21218, USA

mxyang@lnm.imech.ac.cn (M. X. Yang), Tel.: 861082543217.

fpyuan@Inm.imech.ac.cn (F. P. Yuan), Tel.: 861082544409.

qingge.xie@ustb.edu.cn(Q. G. Xie), Tel.: 861082375387.

ydwang@mail.neu.edu.cn(Y. D. Wang), Tel.: 861082375387.

ema@jhu.edu (E. Ma), Tel.: 14105168601.

*Corresponding author: xlwu@imech.ac.cn (X. L. Wu), Tel.: 861082543957 


\begin{abstract}
We report a detailed study of the strain hardening behavior of a Fe-16Mn-10Al-0.86C5Ni (weight percent) high specific strength (i.e. yield strength-to-mass density ratio) steel (HSSS) during uniaxial tensile deformation. The dual-phase ( $\gamma$-austenite and B2 intermetallic compound) HSSS possesses high yield strength of 1.2-1.4 GPa and uniform elongation of 18-34\%. The tensile deformation of the HSSS exhibits an initial yield-peak, followed by a transient characterized by an up-turn of the strain hardening rate. Using synchrotron based high-energy in situ X-ray diffraction, the evolution of lattice strains in both the $\gamma$ and B2 phases was monitored, which has disclosed an explicit elasto-plastic transition through load transfer and strain partitioning between the two phases followed by co-deformation. The unloading-reloading tests revealed the Bauschinger effect: during unloading yield in $\gamma$ occurs even when the applied load is still in tension. The extraordinary strain hardening rate can be attributed to the high back stresses that arise from the strain incompatibility caused by the microstructural heterogeneity in the HSSS.
\end{abstract}

Keywords: high specific strength steel, dual-phase nanostructure, strain hardening, ductility, in situ high-energy X-ray diffraction 


\section{Introduction}

Steels are the strongest ductile bulk materials currently available [1-7]. High-strength and high-ductility steels are needed in various industrial sectors such as automobiles, aviation, aerospace, power, transport, and building construction. Such steels have been developed based on several design principles; typical categories include the transformation-induced plasticity (TRIP) steels [8,9], twinning-induced plasticity (TWIP) steels [10, 11], dual-phase (DP) steels $[12,13]$, nano-structured steels $[14,15]$, and even hypereutectoid steel wires with ultrahigh (6.35 GPa) tensile strength [16].

Recently, the high-aluminium low-density steels have been actively studied for the purpose of increasing the specific strength (i.e. yield strength-to-mass density ratio) $[4,5$, 17-27]. These low-density steels, mainly based on an Fe-Al-Mn-C alloy system containing high contents of $\mathrm{Mn}(16-28$ wt.\%), $\mathrm{Al}(3-12$ wt.\%) and $\mathrm{C}(0.7-1.2$ wt.\%), consist of face-centred cubic (fcc) austenite matrix and body-centred cubic (bcc) ferrite matrix and finely dispersed nanometre-sized $\kappa$-carbides of $(\mathrm{Fe}, \mathrm{Mn})_{3} \mathrm{AlC}$ type (the so-called TRIPLEX steel) [18,19]. Recently, Kim et al. [27] showed a new variation: their Fe-16Mn-10Al-0.86C-5Ni high specific strength steel (HSSS) has a hard FeAl-type (B2) intermetallic compound as the strengthening second phase, and the alloying of Ni catalyzes the precipitation of $\mathrm{B} 2$ particles in the fcc matrix. The combination of specific strength and elongation is outstanding for this HSSS, when compared with other high-specific-strength alloys [27].

In developing various high strength steels aforementioned, a primary issue is the strain 
hardening capability. Strain hardening is a prerequisite for large uniform tensile ductility. However, the mechanism of strain hardening remains an open issue for most high strength steels $[5,22,27]$, because they deform very heterogeneously due to their inhomogeneous microstructures. Even for an initial single-phase alloy, for instance TWIP and TRIP steels, deformation twins and martensite formation make the strain hardening behavior complex [20, 22]. Bhadeshia [28] pointed out that in TRIP steels it is unlikely that the large tensile elongation is predominantly caused by the transformation from austenite into martensite alone. The martensite colonies act as strong inclusions, akin to reinforcing components in a composite, and should have also played a role in strain hardening [29, 30]. A similar conclusion has been reached for TWIP steels where the twinning strain itself makes a significant though small contribution to the total elongation [31].

Indeed, plastic deformation in most high strength steels, much like in composites, is characterized by pronounced plastic heterogeneity between the constituent phases, as well as among grains with different orientations and mechanical responses towards an externally applied load. This causes complex internal stresses, which develop because of intra- and inter-granular variations of plastic strain. The load redistribution and strain partitioning resulting from the microstructural heterogeneity enable a high capacity of strain hardening, affecting the large ductility. The high internal stresses have in fact been reported to contribute to strain hardening and large ductility in TRIP steels [32], TWIP steels [33, 34, 35], nano-composites [36, 37], and dual-phase alloys [38, 39].

The development of internal stresses during deformation of an inhomogeneous micro- 
structure with yield stress mismatch has been well described before [13, 40, 41]: upon tensile loading, plastic yield starts in the soft phase, and the applied load will be transferred from the soft phase to the hard one that is still in elastic state. Thus, internal stresses will build up at the phase interfaces. Upon unloading, the macroscopic stress remains higher than the stress in the soft phase until it reaches the unloaded state, where the soft phase is subjected to an (elastic) compression stress (a tensile stress in the hard phase) $[42,43]$. If the two-phase alloy is subsequently subjected to compressive loading, it initially behaves elastically until the soft phase enters the plastic regime in compression, a situation that will take place at a much lower absolute stress compared to the tensile loading case because of the initial compression of the soft phase. A consequence is an asymmetry in the forward (tensile) and reverse (compressive) yield stresses. Such a phenomenon is known as the Bauschinger effect $[35,38,44]$. Recently, the use of diffraction techniques has supplanted this macroscopic description of internal stresses by the measurements of lattice strains in individual phases [45, 46]. The unload-reload tests $[36,38,47]$ are also used for the study of internal stresses in thin films or composite wires where compression cannot be applied.

In this paper, we analyze the strain hardening in the Fe-16Mn-10Al-0.86C-5Ni HSSS composed of a $\gamma$-austenite matrix containing the B2 FeAl second phase. Based on in situ high energy X-ray diffraction data, the lattice strain evolution in both phases has been monitored and then used to correlate with the mechanical responses such as the stress and strain partitioning, the elasto-plastic transition and co-deformation, and the back-stressinduced strain hardening. Different from Kim et al. [27], who treated this HSSS as a case of 
precipitation strengthening with brittle and non-deformable B2 FeAl, here we show that this steel is better understood as a dual-phase microstructure, with plastic behavior much like a composite. In particular, the B2 phase is deformable, with significant strain hardening capability.

\section{Materials and experimental procedures}

\subsection{Materials}

Similar to the procedures in Ref. [27], an Fe-16Mn-10A1-0.86C-5Ni (wt.\%) HSSS was produced using arc melting in a high frequency induction furnace under pure argon atmosphere, and then cast to a cylindrical ingot with a diameter of $130 \mathrm{~mm}$ and length of 200 $\mathrm{mm}$. The actual chemical composition of the ingot was determined to be Fe-16.4Mn-9.9Al -0.86C-4.8Ni-0.008P-0.004S (wt.\%). The ingot was homogenized at $1180{ }^{\circ} \mathrm{C}$ for 2 hours, hot forged in between $1150{ }^{\circ} \mathrm{C}$ and $900{ }^{\circ} \mathrm{C}$ into slabs with a thickness of $14 \mathrm{~mm}$, and hot-rolled with a starting temperature of $1050{ }^{\circ} \mathrm{C}$ into strips with a thickness $7.3 \mathrm{~mm}$. The hot-rolled striped were finally cold rolled to sheets with the final thickness of $1.5 \mathrm{~mm}$. No cracks were detected on the surfaces of the cold-rolled sheets. The final annealing of the cold-rolled sheets was conducted at $900{ }^{\circ} \mathrm{C}$ for 2-15 minutes followed immediately water quenched.

\subsection{Mechanical property tests}

The dog-bone-shaped plate tensile specimens, with a gauge length of $18 \mathrm{~mm}$ and width of $4 \mathrm{~mm}$, were cut from the annealed sheets with longitudinal axes parallel to the rolling direction. All specimens were mechanically polished prior to tensile tests in order to remove 
surface irregularities and to guarantee an accurate determination of the cross-sectional area. The quasi-static, uniaxial tensile tests were carried out using an MTS Landmark testing machine operating at a strain rate of $5 \times 10^{-4} \mathrm{~s}^{-1}$ at room temperature. The tensile loadunload-reload (LUR) tests were conducted. The condition for LUR tests was the same as that of monotonic tensile test. All tensile tests were conducted using a $10 \mathrm{~mm}$ gauge extensormeter to monitor the strain. The resolutions for stress and strain measurements were $1.0 \times 10^{-2} \mathrm{MPa}$ and $1.0 \times 10^{-5}$, respectively. Vickers micro-hardness indentations $(25 \mathrm{~g}$ load $)$ were made at the ends of the gauge section to check the error in strain measurements by means of an optical traveling microscope. The tensile testing was performed five times on average for each condition to verify the reproducibility of the monotonic and cyclic tensile stress-strain curves.

\subsection{Synchrotron based high energy $\mathrm{X}$-ray diffraction}

In-situ high energy X-ray diffraction measurements were carried out on the beam-line 11-ID-C, at the Advanced Photon Source (APS), Argonne National Laboratory, USA. The experimental set-up was detailed in Ref. [46]. Dimensions of the tensile specimen in the gauge part were $10 \mathrm{~mm}$ (length) $\times 3 \mathrm{~mm}$ (width) $\times 0.5 \mathrm{~mm}$ (thickness). During tensile loading, a monochromatic X-ray beam with energy $105.1 \mathrm{keV}(\lambda=0.11798 \AA)$ and beam size of $500 \mu \mathrm{m}$ (height) $\times 500 \mu \mathrm{m}$ (width) was used. A 2-D detector was placed $2 \mathrm{~m}$ behind the tensile sample to record the scattering intensity. Crystallographic planes were determined from the diffraction patterns and the lattice strains were calculated from the change of the measured inter-planar spacing. The in situ tensile testing of three times was performed to 
verify the reproducibility.

\subsection{Microstructural characterization}

Optical microscopy (OM, Olympus BX51) and scanning electron microscopy (SEM, JSM-7001F) were used to characterize the microstructure of the HSSS before and after tensile tests. The major and minor axis lengths of the $\gamma$ grains, and lamellar and granular B2 grains were measured by the linear intercept method following the procedures given in ASTM E1382, and at least 600 target objects were measured for each corresponding statistical distribution.

A transmission electron microscope (TEM, JEM-2100) and a high-spatial resolution analytical electron microscope (HRTEM, FEI Tecnai G20) both operated at $200 \mathrm{kV}$ for examinations of the typical microstructural features in $\gamma$ and B2 grains. Thin foils for TEM observations were cut from the gauge sections of tensile samples, mechanically ground to about $50 \mu \mathrm{m}$ thick and finally thinned by a twin-jet polishing facility using a solution of $5 \%$ perchloric acid and $95 \%$ ethanol at $-20{ }^{\circ} \mathrm{C}$.

In addition, the microstructural features of $\mathrm{B} 2$ precipitates were also examined by electron back-scattered diffraction (EBSD) using a high-resolution field emission Cambridge S-360 SEM equipped with a fully automatic Oxford Instruments Aztec 2.0 EBSD system (Channel 5 Software). During the EBSD acquisition, a scanning area of $10 \times 14 \mu \mathrm{m}^{2}$ was chosen and a scanning step of $0.03-0.08 \mu \mathrm{m}$ was performed. Due to spatial resolution of the EBSD system, the collected Kikuchi patterns can be obtained automatically at a minimum step of $0.02 \mu \mathrm{m}$ and correspondingly misorientations less than $2^{\circ}$ cannot be identified. The 
longitudinal sections of samples for EBSD examinations were mechanically polished carefully followed by electro-polishing using an electrolyte of 90 vol.\% acetic acid and 10 vol.\% perchloric acid with a voltage of $40-45 \mathrm{~V}$ at about $-40{ }^{\circ} \mathrm{C}$ in a Struers LectroPol-5 facility.

\section{Experimental results}

\subsection{Microstructural characterization}

Figure 1a is an optical microscope image of the longitudinal section of the hot forged sample. Two phases are visible. One is the equi-axed grains of recrystallized fcc $\gamma$-austenite, while the other is the thick lamellar B2 phase parallel to the rolling direction. After cold rolling with a rolling strain of $80 \%$, the $\gamma$ grains change from granular to elongated shape, as shown in Fig. 1b. The B2 phase exhibits a much reduced thickness, indicative of its capability for plastic deformation. After annealing at $900^{\circ} \mathrm{C}$ for 2 minutes, as shown in Fig. 1c, a large number of granular B2 phase precipitates from $\gamma$. Figure 1d shows the high resolution electron back-scattered diffraction (EBSD) image. It is seen that B2 is much inclined to precipitate at both the grain boundaries and triple junctions of $\gamma$ grains, instead of their interiors. This is further evidenced by an enlarged EBSD image as shown in Fig. 1e, where $\gamma$ grains (upper) and B2 phase (lower) are marked in color. Little precipitation is visible inside the interiors of the $\gamma$ grains. Fig. 1f is a transmission electron microscopic (TEM) image showing both the $\gamma$ and B2 grains. They are nearly free of dislocations due to annealing at high temperatures. Annealing twins are often seen in the $\gamma$ grains. The B2 grains are seldom observed inside $\gamma$. 
The above microstructural evolution is similar to that reported by Kim et al. [27], except for B2 precipitation. Kim et al. observed the B2 phase in three different morphologies, namely stringer bands parallel to the rolling direction (type 1), fine B2 particles of sizes 200 $\mathrm{nm}$ to $1 \mu \mathrm{m}$ (type 2) at phase interfaces, and finer particles of sizes 50 to $300 \mathrm{~nm}$ inside $\gamma$ grains (type 3). These finer B2 grains precipitate along shear bands in the non-recrystallized coarse $\gamma$ grains. The volume fraction of B2 in these different types was not reported.

Figs. 2a-c show the statistical distribution of the grain size in the $\gamma$ phase, and in granular and lamellar B2, respectively, after annealing. Several hundreds of grains were counted, in extensive EBSD and TEM observations. It is seen that the $\gamma$ grains are nearly equi-axed with the mean length $(\bar{l})$ and mean width $(\bar{w})$ of 1.67 and $1.32 \mu \mathrm{m}$, respectively, and an aspect ratio $(\alpha)$ of 1.35. $\alpha$ of the granular and lamellar B2 is larger, at 1.52 and 4.35, respectively. It is interesting to note that both $\bar{l}$ and $\bar{w}$ are less than $1 \mu \mathrm{m}$ for granular B2, and $\bar{w}$ is also less $1 \mu \mathrm{m}$ for lamellar B2.

The volume fraction of granular and lamellar B2 is $7.5 \%$ and $14.5 \%$, respectively. Hence, it is more reasonable to consider the present HSSS as a microstructure composed of two phases, with B2 as a micrometer-sized co-existing phase rather than nano-precipitates in a precipitation-hardened $\gamma$ matrix.

Fig. 3 is the XRD spectrum of the HSSS after annealing at $900^{\circ} \mathrm{C}$ for 2 minutes. The diffraction peaks of fcc $\gamma$-austenite and bcc B2 are clearly identified.

\subsection{Tensile Properties}


Fig. 4 shows the tensile properties of the HSSS. Fig. 4a displays the engineering stress versus strain $(\sigma-\varepsilon)$ curves. The as-rolled sample yields at a strength of nearly 2 GPa but soon necks (curve A). After annealing at various temperatures, the tensile uniform elongation increases but with a decrease of strength, as can be seen in the $\sigma-\varepsilon$ curves from B to D. The combination of both the strength and ductility is similar to those reported in Ref. [27], which are also included (dotted lines) in Fig. 4 a for comparison. Note that the rolling strain is $80 \%$ in the present case, which is larger than the $66 \%$ in Ref. [27]. As a summary of the mechanical properties measured so far for high specific strength steels, Figs. $4 \mathrm{c}$ and d compare the tensile properties of our HSSS with that of Kim et al. [27], as well as with the conventional Fe-Mn-Al-C based austenitic [5,11,24], duplex [20,25] and triplex $[17,23,26]$ steels. As can be seen, the HSSS in the present study shows an outstanding combination of the specific yield strength (SYS) and uniform elongation, while exhibiting an acceptable combination of the yield strength-to-ultimate tensile strength (YS-to-UTS) ratio and the uniform elongation. These features indicate that the deformation mechanisms lie behind the present HSSS are effective in simultaneously enhancing the ductility and strength of the steel by virtue of increase in the strain hardening rate.

Interestingly, all the $\sigma-\varepsilon$ curves in Fig. 4a show non-continuous yielding. A yield-peak appears first, followed by a transient deformation stage, seen as a concave segment on the $\sigma-\varepsilon$ curve over a range of strains. This is distinctly different from the continuous yielding (at strain rate of $10^{-3} \mathrm{~s}^{-1}$ ) in the same HSSS reported previously by Kim et al. [27]. Fig. 4b gives the strain hardening rate $\left(\Theta=\frac{\partial \sigma}{\partial \varepsilon}\right)$ versus true stress curves. The hardening rate $\Theta$ evolves in 
a similar trend. That is, $\Theta$ drops rapidly first, even to below zero in curves $\mathrm{C}$ and $\mathrm{D}$, followed by an up-turn to reach its maximum. In particular, as seen in the inset of Fig. 4a, the $\Theta$ maximum corresponds to the inflection point marked by ,׳’. In other words, $\Theta$ recovers to its maximum when the transient ends. Such a transient was widely observed before [48-51], indicative of the Bauschinger effect (BE). It usually appears for alloys of multi-phases with varying yield stresses, over a strain regime corresponding to heterogeneous elasto-plastic deformation [36,38]. Similar behavior of $\Theta$ has also been observed recently in gradient structure [52,53] and heterogeneous lamella structure [41].

\subsection{Strain hardening due to back stresses}

To probe the mechanism of strain hardening and especially the origin of the $\Theta$ up-turn, LUR tests (Fig. 5a) were conducted. Two typical features are seen in unload-reload cycles. One is the hysteresis loop (Fig. 5b), while the other is the unload yield effect, i.e. yield-drop $\Delta \sigma_{\mathrm{y}}$ (inset in Fig. 5b), upon each reload. These are schematically depicted in Fig. 5c. These hysteresis loops are evidence of the BE. Interestingly, the hysteresis loop appears even from the onset of the transient (upper panel in Fig. 4b). Moreover, this BE appears to be strong: the reverse plastic flow $\left(\sigma_{\text {rev }}\right)$ starts even when the overall applied stress is still in tension during unloading. The BE could be described by the reverse plastic strain $\left(\varepsilon_{\mathrm{rp}}\right)$, Fig. $5 \mathrm{c}$, which increases as plastic strains increase (Fig. 5d).

The most common explanation for the hysteresis loops in interrupted tensile tests is based on the back stresses resulting from inhomogeneous plastic deformation $[36,38,54,55]$. Here, the macroscopic stress is separated into the internal stress $\left(\sigma_{\text {back }}\right)$ and effective stress 
( $\left.\sigma_{\text {eff }}\right)$ [56]. The former is generally associated with a long-range stress on mobile dislocations and the latter is the stress required for a dislocation to overcome local obstacles. $\sigma_{\text {back }}$ can be calculated as [56],

$$
\sigma_{\mathrm{back}}=\frac{\left(\sigma_{\mathrm{flow}}+\sigma_{\mathrm{rev}}\right)}{2}-\frac{\sigma *}{2}
$$

where $\sigma_{\text {flow }}$ is the flow stress upon unloading and $\sigma^{*}$ is the thermal part of the flow stress. These parameters are defined in Fig. 5c. The values of $\sigma_{\text {rev }}$ are monitored, as shown in Fig. 5e, at three selected strain offsets, with increasing deviation from the initial linear segment on each loop.

Fig. $5 \mathrm{f}$ shows the $\sigma_{\text {back }}$, and the hardening rate due to back stresses, $\Theta_{\text {back }}$, as the tensile strain increases, based on $\sigma_{\text {rev }}$ calculated at $0.02 \%$ offset. With increasing strain, $\sigma_{\text {back }}$ increases, while $\Theta_{\text {back }}$ decreases. Interestingly, $\Theta_{\text {back }}$ is initially much higher than $\Theta_{\text {total }}$ but shows a steep drop during the transient. This indicates that $\sigma_{\text {back }}$ is responsible for the $\Theta$ up-turn. Meanwhile, when selecting $\sigma_{\text {rev }}$ with different strain offset (Fig. 5e), the similar trend appears in $\Theta_{\text {back }}$, even though the $\sigma_{\text {back }}$ values differ significantly.

\subsection{Load transfer and strain partitioning}

During the plastic deformation, the softer $\gamma$ grains are easier to deform than the harder B2 grains. This causes plastic strain partitioning where the soft grains carry higher plastic strains. As seen in Figs. 6a-c, the present HSSS is a dual-phase alloy. That is, the load transfer and strain redistribution will occur due to the highly heterogeneous microstructure. In situ high energy X-ray diffraction measurements have been employed to provide atomic-level strains 
to help understand the underlying mechanism.

\subsubsection{Load transfer revealed by in situ diffraction measurements}

Fig. 6a shows both the true $\sigma-\varepsilon$ and $\Theta-\varepsilon$ curves, measured in situ together with the high-energy X-ray diffraction measurements of the lattice strain. The stress-strain behavior and the $\Theta$ up-turn are similar to those observed in Fig. 4a. The stress partitioning during tensile loading was reflected from the lattice strain evolution of both phases. Fig. $6 \mathrm{~b}$ is the lattice strain as a function of the applied tensile strain in the axial (loading) and transverse direction, respectively, in both the $\gamma$ and B2 phases. The lattice strains were calculated using $\left(d^{\mathrm{hkl}}-d_{0}^{\mathrm{hkl}}\right) / d_{0}^{\mathrm{hkl}}$, where $d_{0}^{\mathrm{hkl}}$ is the d-spacing of the $(h k l)$ plane at zero applied stress. As the applied strain increases, both the $\varepsilon_{\gamma}^{111}$ and $\varepsilon_{\mathrm{B} 2}^{110}$ in axial direction roughly follow a three-stage evolution. In stage I, both the $\varepsilon_{\gamma}^{111}$ and $\varepsilon_{\mathrm{B} 2}^{110}$ coincide well and increase linearly. In stage II, $\varepsilon_{\gamma}^{111}$ deviates from the straight line at the strain of 0.06 , while $\varepsilon_{\mathrm{B} 2}^{110}$ still keeps rising linearly. A close-up is shown in Fig. 6c. As the tensile strain increases further to $\sim 0.07$, a rapid drop of $\varepsilon_{\mathrm{B} 2}^{110}$ appears. In stage III, both $\varepsilon_{\gamma}^{111}$ and $\varepsilon_{\mathrm{B} 2}^{110}$ begin to rise once again, but with obviously different slopes.

Fig. 6d shows the high energy X-ray diffraction pattern. As seen in Fig. 6e, both $\{111\}_{\gamma}$ and $\{110\}_{\mathrm{B} 2}$ diffraction peaks maintain constant intensity initially, while their positions shift to smaller $2 \vartheta$ along the axial direction; an opposite trend appears in transverse direction (see Fig. 6f). For the axial strains over the range studied, the intensities of all the diffraction peaks remain almost constant. A sudden increase in the full width at half-maximum (FWHM) is visible for $\{111\}_{\gamma}$ and $\{110\}_{\mathrm{B} 2}$, respectively, at a strain of 0.06 
and 0.07. At the same time, it is interesting to observe that the $\{110\}_{\mathrm{B} 2}$ peak starts to diminish in the transverse direction. In addition, both $\{200\}_{\mathrm{B} 2}$ and $\{211\}_{\mathrm{B} 2}$ peaks lower their heights gradually with plastic deformation and disappear eventually, similar to what has happened to $\{110\}_{\mathrm{B} 2}$.

\subsubsection{Strain partitioning from aspect ratio measurements}

The strain partitioning is such that $\gamma$ bears a large amount of plastic strains. This is measured by the aspect ratio changes before and after tensile tests, monitored also in sample D. The aspect ratio information before tensile testing was in Figs. 2 a to c, for $\gamma$, granular B2, and lamellar B2, respectively. Figs. 7a-c show the SEM images of the longitudinal section after tensile testing to a true strain of $\sim 26 \%$. Most of the initially equi-axed $\gamma$ grains (Fig. 2c) now become strongly elongated (gray contrast) along the tensile direction as seen in the inset of Fig. 7a. The mean spacing $\bar{l}$ and $\bar{w}$, and aspect ratio $\alpha$ in the tensile direction are shown in Figs. 7d-f. The mean true strain in each phase can be calculated as $\bar{\varepsilon}=(2 / 3) \cdot \ln \left(\alpha_{\text {after }} / \alpha_{\text {before }}\right)$. The derivation of the formula and the calculation method can be found in Ref. [41]. The strain experienced by $\gamma$, granular and lamellar B2, respectively, is about $27 \%, 7 \%$, and $1 \%$, respectively, at the total applied strain of $\sim 26 \%$.

\section{Discussion}

\subsection{Plastic deformation in HSSS}

Fig. 6 shows three stages of the lattice strain evolution with applied axial strains in the $\gamma$ and B2 phases. In stage I, both $\gamma$ and B2 phases deform elastically, with a linear increase of 
both $\varepsilon_{\gamma}^{111}$ and $\varepsilon_{\mathrm{B} 2}^{110}$. In stage II, as shown in Fig. $6 \mathrm{c}, \varepsilon_{\gamma}^{111}$ is the first to deviate from linearity at a strain of 0.06 , while $\varepsilon_{\mathrm{B} 2}^{110}$ continues to rise linearly. This indicates the onset of yielding in $\gamma$, at the microscopic level, due to its lower yield stress than that of B2 [39]. Exactly from this very moment, the stress shifts from $\gamma$ to the still elastic B2. With further deformation, the load shared by $\gamma$ will decrease. This leads to a drop in $\varepsilon_{\gamma}^{111}$ and a continued rise in $\varepsilon_{\mathrm{B} 2}^{110}$, soon after this micro-yielding. This stage is marked as $\mathrm{II}_{1}$ in Fig. 6c, reflecting the "grain to grain yielding" in $\gamma$ due to the varying Schmid factor and strain hardening of individual grains $[39,57]$. As the strain increases to 0.07 , a rapid drop of $\varepsilon_{\mathrm{B} 2}^{110}$ appears, which signals the onset of the stage $\mathrm{II}_{2}$. This drop of $\varepsilon_{\mathrm{B} 2}^{110}$ indicates declined stresses that are delivered from $\gamma$ to B2 through phase interfaces. That is, the B2 phase starts to yield. The fact that $\varepsilon_{\mathrm{B} 2}^{110}$ still rises to large strains rules out the possibility of failure at the $\gamma / \mathrm{B} 2$ interfaces. With a severe stress concentration built up at the phase interfaces between $\gamma$ and $\mathrm{B} 2$ during stage $\mathrm{II}_{1}$, the B2 also begins to deform to provide necessary accommodation between the two phases. Hence, both strains and stresses will relax to a large degree at the $\gamma / \mathrm{B} 2$ phase interfaces. As a result, $\varepsilon_{\mathrm{B} 2}^{110}$ drops rapidly. As shown in Fig. 6e, an increase in FWHM of the $\{111\}_{\gamma}$ and $\{110\}_{\mathrm{B} 2}$ diffraction peak at axial strain of 0.06 and 0.07 is due to dislocation generation in the crystal, indicative of the onset of micro-yielding in $\gamma$ and B2, respectively. Hence, stage II indicates the elasto-plastic transition, as the $\gamma$ phase deforms plastically first ( $\left.\mathrm{II}_{1}\right)$ followed by the B2 phase $\left(\mathrm{II}_{2}\right)$.

In stage III, a rise in both $\varepsilon_{\gamma}^{111}$ and $\varepsilon_{\mathrm{B} 2}^{110}$ is visible once again at strains larger than 0.088 . This indicates the onset of the co-deformation in both $\gamma$ and B2. Interestingly, the slope 
$\left(\partial \varepsilon_{\mathrm{B} 2}^{110} / \partial \varepsilon_{\text {axial }}\right)$ for lattice strains to rise in B2 is much larger than the $\partial \varepsilon_{\gamma}^{111} / \partial \varepsilon_{\text {axial }}$. This indicates that the load transfer occurs once again during the co-deformation of two phases. As a result, strain partitioning occurs between the $\gamma$ and B2 phases, as is further evidenced by the aspect ratio measurements shown in Fig. 7. Moreover, an increase in $\varepsilon_{\mathrm{B} 2}^{110}$ with axial strains is significant, indicating the strong and continued strain hardening in B2 all the way to final fracture. In addition, an increase in both $\varepsilon_{\gamma}^{111}$ and $\varepsilon_{\mathrm{B} 2}^{110}$ also indicates the recovery of hardening capacity in both $\gamma$ and B2 in this stage. Both $\gamma$ and B2 strain harden and participate in the load sharing, even though B2 carries the most part of the applied load. As the axial strain increases further, the intensities of all the diffraction peaks stay almost constant, as seen in Fig. 6e. This indicates the co-deformation of both the $\gamma$ and B2 phases.

As seen in Fig. 6f, the $\{110\}_{\mathrm{B} 2}$, as well as $\{200\}_{\mathrm{B} 2}$ and $\{211\}_{\mathrm{B} 2}$ peaks, begin to disappear with strains beyond the inflection point during the tensile testing. This indicates crystal re-orientation, e.g. rotation of the grains, in the B2 phase for the purpose of accommodating strain.

\subsection{Strain hardening}

By comparing Figs. 6a and 6c, the onset of B2 yielding corresponds to the rapid drop of $\Theta$, while the $\Theta$ starts its up-turn at the end of this yielding. This means that the stressstrain curve in the transient before the inflection point corresponds to the elasto-plastic transition. The interesting $\Theta$ evolution (Figs. 4b and Fig. 6a) originates, therefore, from the dual-phase nature of plastic deformation in HSSS. Under tensile loading, $\gamma$ will plastically deform first. However, due to the constraint by the still elastic B2, dislocations in $\gamma$ are piled 
up and blocked at phase interfaces. Geometrically necessary dislocations (GNDs) will be generated at phase interfaces due to the strain incompatibility of the two phases $[40,58]$. This produces the internal stresses to make it difficult for dislocations to slip in $\gamma$ grains until B2 grains start to yield at a larger global strain. The long-range back stresses develop as a result. Additionally, the intra-granular internal stresses also develop due to the dislocations inside the $\gamma$ grains, along with the "grain to grain yielding" due to the misfit plastic strains among neighboring $\gamma$ grains [59]. This is the reason of a very high $\Theta_{\text {back }}$ at the onset of the elasto-plastic transition as shown in Fig. 5f. Therefore, the high strain hardening rate is originated from both the back stress hardening and forest dislocation hardening in $\gamma$. Plastic incompatibilities that result from microstructural heterogeneity induce large internal stresses. Also, after the whole B2 grains yield, $\Theta$ is sustained at a level corresponding to the back stresses resulting from the strain incompatibility, together with dislocation multiplication in both $\gamma$ and B2.

Note that the B2 grains are plastically deformable and can store dislocations, as is shown in Fig. 8 by TEM observations. During the co-deformation of both the $\gamma$ and B2 phases (stage III), as seen in Figs. $6 \mathrm{~b}$ and c, the lattice strain in B2, $\varepsilon_{B 2}^{110}$, increases with the axial strain, $\varepsilon_{\text {axial }}$. But the slope $\partial \varepsilon_{\mathrm{B} 2}^{110} / \partial \varepsilon_{\text {axial }}$ is smaller than that of elastic stage I. If B2 is elastic in stage III, its slope should remain unchanged. This indicates that plastic deformation does occur in B2, which is further supported by the aspect ratio measurements (Fig. 7). The average macroscopic plastic strain in the granular and lamellar B2 is $10 \%$, and $2 \%$, respectively. On the other hand, the slope for lattice strains to rise in B2 is much larger than 
that in $\gamma$. This indicates even stronger strain hardening in B2 than that in $\gamma$. The load transfer and back stress is probably responsible for this strong strain hardening in B2. Moreover, the observation of a high density of dislocations after tensile testing lends support to the assertion that B2 can sustain strain hardening during tensile deformation.

In addition, the strains should be continuous at the phase interfaces between $\gamma$ and B2, with a strain gradient near the phase interfaces [60,61]. As a result, the GNDs will be generated to accommodate the strain gradient [52], contributing to the dislocation pile-up near phase interfaces that elevates the back stresses $[37,40,62]$. In other words, the back stress associated with strain partitioning should have contributed to the observed high strain hardening rate. Moreover, $\gamma$ grains are observed to be stretched along their length direction by as much as 100 pct on average (by comparison of $\bar{l}$ before and after tensile testing in Fig. 2a and Fig. 7d); this plastic deformation is expected to increase the dislocation density in the interior of $\gamma$ grains.

\subsection{Unloading yield effect}

As seen in Fig. 4a, there is a yield-drop in the initial yielding. The inset in Fig. 5b and Fig. $5 \mathrm{~d}$ also indicate that the new yield stress upon each reloading is also higher than the flow stress at the point of unloading. These two observations may have the same underlying mechanism. Such a behavior resembles the yield-drop phenomenon in carbon steels [63].

The yield-drop phenomenon in an interrupted tensile test was first observed in a single crystal $\mathrm{A} 1-4.5 \% \mathrm{Cu}$ alloy [64]. A more systematic study on commercial aluminum alloys 
2024, 7075and 6061 was reported subsequently by Nieh and Nix [65] who used the term "unloading yield effect" to describe this phenomenon. We shall also use this latter term as it avoids being ambiguous with the distinct yield point phenomenon observed in carbon steels. Nieh and Nix [65] proposed a qualitative model based on the healing of sheared coherent precipitates for the appearance of the unloading yield effect in $\mathrm{Al}$ alloys. According to their model, the precipitates sheared by moving dislocations are quickly healed by diffusion processes when plastic deformation is paused by unloading. However, this mechanism does not seem to be applicable if a sample with little precipitates still exhibits unloading yield effect.

The unloading yield effect may be understood as follows. Once unloaded, the B2 phase becomes elastic. Upon reloading, firstly, the B2 stays elastic while $\gamma$ begins to deform plastically. The yield peak appears once again upon reloading due to the load transfer. As the tensile strain increases, the mobile dislocation density decreases in $\gamma$ and a higher stress is needed for the $\gamma$ to yield, leading to an increased $\Delta \sigma_{\mathrm{y}}$. Secondly, once the B2 yields, rapid relaxation of elastic stresses and strains on the $\gamma / \mathrm{B} 2$ interfaces causes the stress-drop.

\section{Conclusions}

We have analyzed the strain hardening process in the Fe-16Mn-10Al-0.86C-5Ni high specific strength steel. As the steel has a heterogeneous microstructure composed of a $\gamma$-austenite matrix containing the $\mathrm{B} 2 \mathrm{FeAl}$ second phase, our treatment is from the perspective of a dual-phase that are both deformable with significant strain hardening capability. In situ high-energy X-ray diffraction revealed the lattice strain evolution in both 
phases. The softer phase deformed first, shedding load to harder regions, eventually causing the latter to deform. The load transfer and strain partitioning unraveled from the in situ data indicates an elasto-plastic transition, with grain-to-grain yielding until the yielding of all grains, in the order of softer $\gamma$ and then harder B2, and finally co-deformation. As such, the atomic-scale information sheds light on the origin of the high back stresses that have been measured, of the pronounced Bauschinger effect, as well as of the rapid yield drop and subsequent up-turn of the strain hardening rate in the transient. The back stress hardening is believed to play a crucial role for the high strain hardening rate that has sustained the large elongation in the HSSS.

\section{Acknowledgements}

This work was financially supported by the National Natural Science Foundation of China (NSFC) under grant Nos. 11572328, 11072243, 11222224, 11472286, and 51471039, the 973 Programs under grant Nos. 2012CB932203, 2012CB937500, and 6138504. E.M. was supported at the Johns Hopkins University by U.S.-DOE-BES, Division of Materials Sciences and Engineering, under Contract No. DE-FG02-09ER46056.

\section{References}

[1] M. Militzer, A synchrotron look at steel, Science 298 (2002) 975-976.

[2] Y. Kimura, T. Inoue, F. Yin, K. Tsuzaki, Inverse temperature dependence of toughness in an ultrafine grain-structure steel, Science 320 (2008) 1057-1060.

[3] F. G. Caballero, H. K. D. H. Bhadeshia, Very strong bainite, Curr. Opin. Solid State Mater. Sci. 8 
(2004) 251-257.

[4] D. Raabe, H. Springer, I. Gutierrez-Urrutia, F. Roters, M. Bausch, J. B. Seol, K. Koyama, P. -P. Choi,

K. Tsuzaki, Alloy design, combinatorial synthesis, and microstructure-property relations for low-density Fe-Mn-Al-C austenitic steels, JOM 66 (2014) 1845-1856.

[5] D. Raabe, C. C. Tasan, H. Springer, M. Bausch, From high-entropy alloys to high-entropy steels, Steel Res. Int. 86 (2015) 1127-1138.

[6] O. Bouaziz, S. Allain, C. P. Scott, P. Cugy, D. Barbier, High manganese austenitic twinning induced plasticity steels: a review of the microstructure properties relationships, Curr. Opin. Solid State Mater. Sci. 15 (2011) 141-168.

[7] T. Furuta, S. Kuramoto, T. Ohsuna, K. Oh-ishi, K. Horibuchi, Die-hard plastic deformation behavior in an ultrahigh-strength Fe-Ni-Al-C alloy, Scr. Mater. 101 (2015) 87-90.

[8] G. Frommeyer, U. Brüx, P. Neumann, Supra-ductile and high-strength manganese-TRIP/TWIP steels for high energy absorption purposes, ISIJ Int. 43(2003) 438-446.

[9] D. Raabe, D. Ponge, O. Dmitrieva, B. Sander, Nanoprecipitate-hardened 1.5 GPa steels with unexpected high ductility, Scr. Mater. 60 (2009) 1141-1144.

[10] O. Bouaziz, S. Allain, C. Scott, Effect of grain and twin boundaries on the hardening mechanisms of twinning-induced plasticity steels, Scr. Mater. 58 (2008) 484-487.

[11] S. Kang, Y. -S Jung, J. -H Jun, Y. -K. Lee, Effects of recrystallization annealing temperature on carbide precipitation, microstructure, and mechanical properties in Fe-18Mn-0.6C-1.5Al TWIP steel, Mater. Sci. Eng. A 527 (2010) 745-751.

[12] Y. I. Son, Y. K. Lee, K. T. Park, C. S. Lee, D. H. Shin, Ultrafine grained ferrite-martensite dual phase steels fabricated via equal channel angular pressing: microstructure and tensile properties, Acta Mater. 53 (2005) 3125-3134.

[13] M. Calcagnotto, Y. Adachi, D. Ponge, D. Raabe, Deformation and fracture mechanisms in fine-and ultrafine-grained ferrite/martensite dual-phase steels and the effect of aging, Acta Mater. 59 (2011) 658-670.

[14] H. K. D. H. Bhadeshia, The first bulk nanostructured metal, Sci. Tech, Adv. Mater. 14 (2013) 014202.

[15] R. Ueji, N. Tsuji, Y. Minamino, Y. Koizumi, Ultragrain refinement of plain low carbon steel by cold-rolling and annealing of martensite, Acta Mater. 50 (2002) 4177-4189.

[16] Y. Li, D. Raabe, M. Herbig, P. P. Choi, S. Goto, A. Kostka, H. Yarita, C. Borchers, R. Kirchheim, Segregation stabilizes nanocrystalline bulk steel with near theoretical strength, Phys. Rev. lett. 113 (2014) 106104.

[17] G. Frommeyer, U. Bruex, Microstructures and mechanical properties of high-strength Fe-Mn-Al-C light-weight TRIPLEX steels, Steel Res. Int. 77 (2006) 627-633. 
[18] R. Rana, C. Lahaye, R. K. Ray, Overview of lightweight ferrous materials: strategies and promises, JOM 66 (2014) 1734-1746.

[19] H. Kim, D. W. Suh, N. J. Kim, Fe-Al-Mn-C lightweight structural alloys: a review on the microstructures and mechanical properties, Sci. Tech. Adv. Mater. 14 (2013) 014205.

[20] S. S. Sohn, H. Song, B. C. Suh, J. H. Kwak, B. J. Lee, N. J. Kim, S. Lee, Novel ultra-high-strength (ferrite + austenite) duplex lightweight steels achieved by fine dislocation substructures (Taylor lattices), grain refinement, and partial recrystallization, Acta Mater. 96 (2015) 301-310.

[21] C. L. Lin, C. G. Chao, J. Y. Juang, J. M. Yang, T. F. Liu, Deformation mechanisms in ultrahigh-strength and high-ductility nanostructured FeMnAlC alloy, J. Alloys Compd. 586 (2014) 616-620.

[22] I. Gutierrez-Urrutia, D. Raabe, Multistage strain hardening through dislocation substructure and twinning in a high strength and ductile weight-reduced Fe-Mn-Al-C steel, Acta Mater. 60 (2012) 5791-5802.

[23] I. Gutierrez-Urrutia, D. Raabe, Influence of Al content and precipitation state on the mechanical behavior of austenitic high-Mn low-density steels, Scr. Mater. 68 (2013) 343-347.

[24] J. D. Yoo, S. W. Hwang, K. T. Park, Factors influencing the tensile behavior of a Fe-28Mn-9Al-0.8 C steel, Mater. Sci. Eng. A 508 (2009) 234-240.

[25] S. W. Hwang, J. H. Ji, E. G. Lee, K. T. Park, Tensile deformation of a duplex Fe-20Mn-9Al-0.6 C steel having the reduced specific weight, Mater. Sci. Eng. A 528 (2011) 5196-5203.

[26] Z. Q. Wu, H. Ding, X. H. An, D. Han, X. Z. Liao, Influence of Al content on the strain-hardening behavior of aged low density Fe-Mn-Al-C steels with high Al content, Mater. Sci. Eng. A 639 (2015) 187-191.

[27] S. H. Kim, H. Kim, N. J. Kim, Brittle intermetallic compound makes ultrastrong low-density steel with large ductility, Nature 518 (2015) 77-79.

[28] H. K. D. H. Bhadeshia, TRIP-assisted steels ?, ISIJ Int. 42 (2002) 1059-1060.

[29] C. C. Tasan, M. Diehl, D. Yan, C. Zambaldi, P. Shanthraj, F. Roters, D. Raabe, Integrated experimental-simulation analysis of stress and strain partitioning in multiphase alloys, Acta Mater. 81 (2014) 386-400.

[30] H. Ghassemi-Armaki, P. Chen, S. Bhat, S. Sadagopan, S. Kumar, A. Bower, Microscale-calibrated modeling of the deformation response of low-carbon martensite, Acta Mater. 61 (2013) 3640-3652.

[31] B. Qin, H. K. D. H. Bhadeshia, Plastic strain due to twinning in austenitic TWIP steels, Mater. Sci. Tech. 24 (2008) 969-973.

[32] S. Cheng, X. L. Wang, Z. Feng, B. Clausen, H. Choo, P. K. Liaw, Probing the characteristic deformation behaviors of transformation-induced plasticity steels, Metall. Mater. Trans. A 39A (2008) 
$3105-3112$.

[33] O. Bouaziz, S. Allain, C. Scott, Effect of grain and twin boundaries on the hardening mechanisms of twinning-induced plasticity steels, Scr. Mater. 58 (2008) 484-487.

[34] J. G. Sevillano. An alternative model for the strain hardening of FCC alloys that twin, validated for twinning-induced plasticity steel, Scr. Mater. 60 (2009) 336-339.

[35] A. A. Saleh, E. V. Pereloma, B. Clausen, D. W. Brown, C. N. Tomé, A. A. Gazder, On the evolution and modelling of lattice strains during the cyclic loading of TWIP steel, Acta Mater. 61 (2013) 5247-5262. [36] L. Thilly, S. Van Petegem, P. O. Renault, F. Lecouturier, V. Vidal, B. Schmitt, H. Van Swygenhoven, A new criterion for elasto-plastic transition in nanomaterials: Application to size and composite effects on $\mathrm{Cu}-\mathrm{Nb}$ nanocomposite wires, Acta Mater. 57 (2009) 3157-3169.

[37] Y. Xiang, J. J. Vlassak, Bauschinger effect in thin metal films, Scr. Mater. 53 (2005): 177-182.

[38] C. W. Sinclair, G. Saada, J. D.Embury, Role of internal stresses in co-deformed two-phase materials, Phil. Mag. 86 (2006) 4081-4098.

[39] S. Harjo, Y. Tomota, D. Neov, P. Lukas, M. Vrana, P. Mikula, Bauschinger effect in alpha-gamma dual phase alloys studied by in situ neutron diffraction, ISIJ int. 42 (2002) 551-557.

[40] M. F. Ashby, The deformation of plastically non-homogeneous materials, Phil. Mag. 21 (1970) 399-424.

[41] X. L. Wu, M. X. Yang, F. P. Yuan, G. L. Wu, Y. J. Wei, X. X. Huang, Y. T. Zhu, Heterogeneous lamella structure unites ultrafine-grain strength with coarse-grain ductility, Proc. Natl. Acad. Sci. USA 112 (2015) 14501-14505.

[42] J. Rajagopalan, J. H. Han, M. T. A. Saif, Bauschinger effect in unpassivated freestanding nanoscale metal films, Scr. Mater. 59 (2008) 734-737.

[43] J. Rajagopalan, C. Rentenberger, H. P. Karnthaler, G. Dehm, M. T. A. Saif, In situ TEM study of microplasticity and Bauschinger effect in nanocrystalline metals, Acta Mater. 58 (2010) 4772-4782.

[44] J. Llorca, A. Needleman, S. Suresh, The Bauschinger effect in whisker-reinforced metal-matrix composites, Scr. Metall. Mater. 24 (1990) 1203-1208.

[45] Z. H. Cong, N. Jia, X. Sun, Y. Ren, J. Almer, Y. D. Wang, Stress and strain partitioning of ferrite and martensite during deformation, Metall. Mater. Trans. A 40A (2009) 1383-1387.

[46] S. Cheng, Y. D. Wang, H. Choo, J. Almer, Y. Lee, P. K. Liaw, An assessment of the contributing factors to the superior properties of a nanostructured steel using in situ high-energy X-ray diffraction, Acta Mater. 58 (2010) 2419-2429.

[47] Z. L. Wang, P. Zheng, Z. H. Nie, Y. Ren, Y. D. Wang, P. Müllner, D. C. Dunand, Superelasticity by reversible variants reorientation in a Ni-Mn-Ga microwire with bamboo grains, Acta Mater. 99 (2015) 373-381. 
[48] T. Hasegawa, T. Yakou, U. F. Kocks, Forward and reverse rearrangements of dislocations in tangled walls, Mater. Sci. Eng. 81 (1986) 189-199.

[49] M. G. Stout, A. D. Rollett, Large-strain Bauschinger effects in fcc metals and alloys, Metall. Trans. A 21A (1990) 3201-3213.

[50] A. Deschamps, B. Decreus, F. De Geuser, T. Dorin, M. Weyland, The influence of precipitation on plastic deformation of Al-Cu-Li alloys, Acta Mater. 61 (2013) 4010-4021.

[51] G. Fribourg, Y. Bréchet, A. Deschamps, A. Simar, Microstructure-based modelling of isotropic and kinematic strain hardening in a precipitation-hardened aluminium alloy, Acta Mater. 59 (2011) 3621-3635. [52] X. L. Wu, P. Jiang, L. Chen, F. P. Yuan, Y. T. Zhu, Extraordinary strain hardening by gradient structure, Proc. Natl. Acad. Sci. USA 111 (2014) 7197-7201.

[53] X. C. Yang, X. L. Ma, J. Moering, H. Zhou, W. Wang, Y. L. Gong, J. M. Tao, Y. T. Zhu, X. K. Zhu, Influence of gradient structure volume fraction on the mechanical properties of pure copper, Mater. Sci. Eng. A 645 (2015) 280-285.

[54] G. D. Moan, J. D. Embury, A study of the Bauschinger effect in Al-Cu alloys, Acta Metall. 27 (1979) 903-914.

[55] H. Mughrabi, Dislocation wall and cell structures and long-range internal stresses in deformed metal crystals, Acta Metall. 31 (1983) 1367-1379.

[56] X. Feaugas, On the origin of the tensile flow stress in the stainless steel AISI 316L at $300 \mathrm{~K}$ : back stress and effective stress, Acta Mater. 47 (1999) 3617-3632.

[57] Y. Tomota, P. Lukas, S. Harjo, J. H. Park, N. Tsuchida, D. Neov, In situ neutron diffraction study of IF and ultra-low carbon steels upon tensile deformation, Acta Mater. 51 (2003) 819-830.

[58] H. Mughrabi, On the role of strain gradients and long-range internal stresses in the composite model of crystal plasticity, Mater. Sci. Eng. A 317 (2001) 171-180.

[59] B. Chen, J. N. Hu, Y. Q. Wang, S. Y. Zhang, S. Van Petegem, A. C. F. Cocks, D. J. Smith, P. E. J. Flewitt, Role of the misfit stress between grains in the Bauschinger effect for a polycrystalline material, Acta Mater. 85 (2015) 229-242.

[60] X. L. Wu, P. Jiang, L. Chen, J. F. Zhang, F. P. Yuan, Y. T. Zhu, Synergetic strengthening by gradient structure, Mater. Res. Lett. 2 (2014) 185-191.

[61] J. J. Li, S. H. Chen, X. L. Wu, A. K. Soh, A physical model revealing strong strain hardening in nano-grained metals induced by grain size gradient structure, Mater. Sci. Eng. A, 620 (2015) 16-21.

[62] A. T. Jennings, C. Gross, F. Greer, Z. H. Aitken, S. W. Lee, C. R. Weinberger, J. R. Greer, Higher compressive strengths and the Bauschinger effect in conformally passivated copper nanopillars, Acta Mater. 60 (2012) 3444-3455.

[63] N. Tsuji, Y. Ito, Y. Saito, Y. Minamino, Strength and ductility of ultrafine grained aluminum and iron 
Revised manuscript submitted to Acta Materialia by Xiaolei Wu et al

produced by ARB and annealing, Scr. Mater. 47 (2002) 893-899.

[64] G. Greetham, R. W. K. Honeycombe, The deformation of single crystals of aluminium 4.5-percent copper alloy, J. Inst. Met. 89 (1960) 13-21.

[65] T. G. Nieh, W. D. Nix, Unloading yield effects in aluminum alloys, Metall. Trans. A, 17A (1986) 121-126. 


\section{Figures and captions}

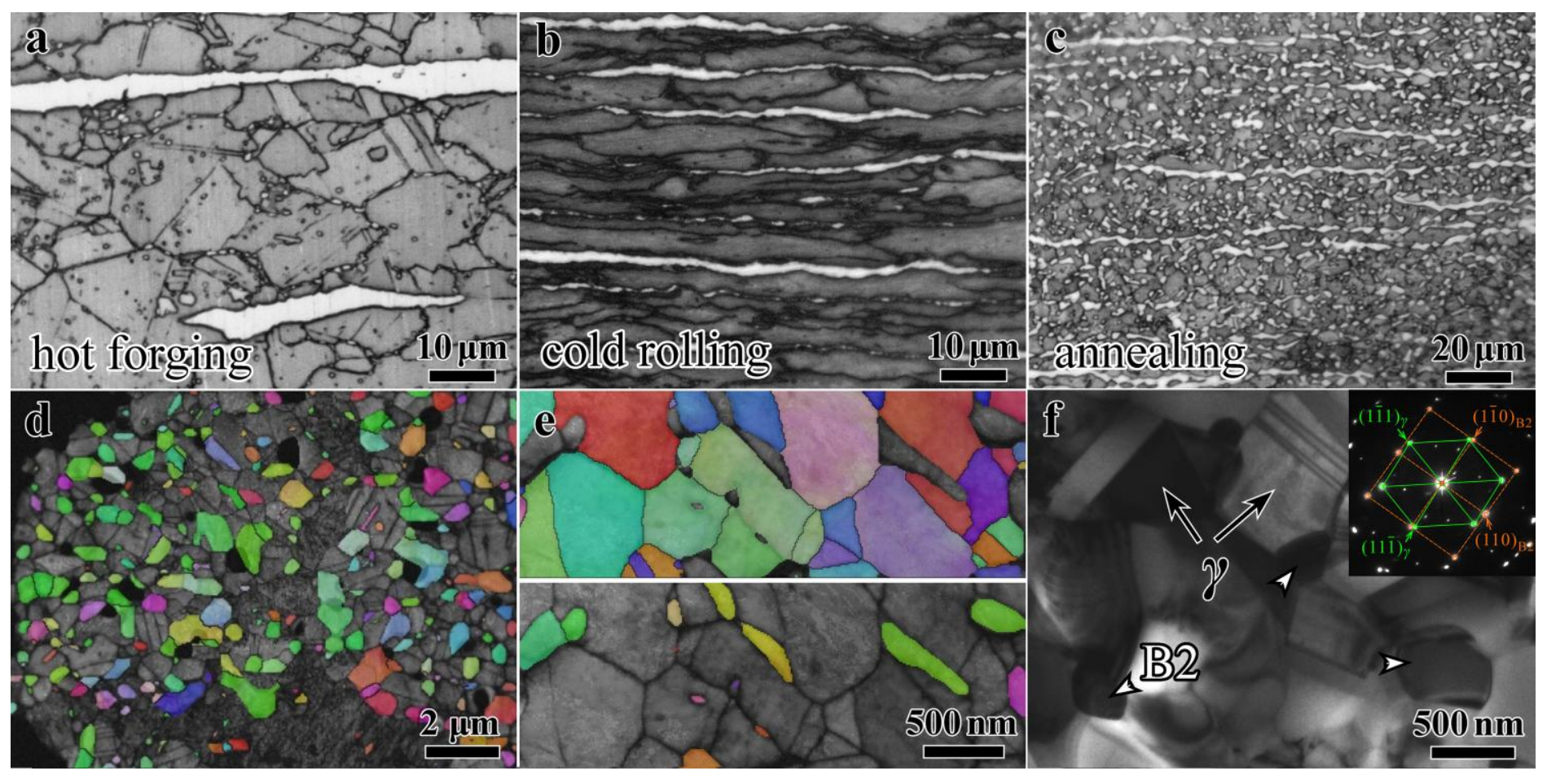

Figure 1 Microstructural characterization of HSSS. a-c. Optical images of longitudinal sections of the HSSS samples after hot forging, further cold rolling, and finally annealing at $900^{\circ} \mathrm{C}$ for 2 minutes, respectively. d. High resolution electron back-scattered diffraction (EBSD) image from c. B2 grains are colored. e. Enlarged EBSD images. Colored grains are $\gamma$ (upper half of e) and B2 (lower half). f. Transmission electron microscope image showing $\gamma$ and B2 dual-phase. Arrows indicate $\gamma$ and triangles indicate B2. The inset shows the indexed selected area diffraction pattern with electron beam closely parallel to both the $[011]_{\gamma}$ and $[001]_{\mathrm{B} 2}$ zone axes. 

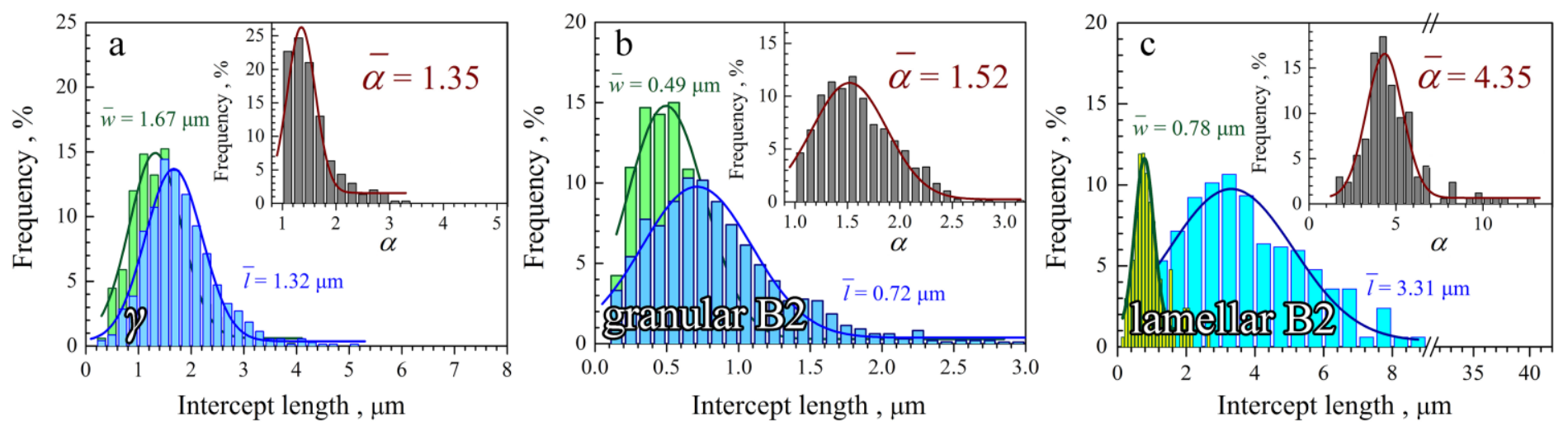

Figure 2 Histograms showing the statistics of the grain size distribution in $\gamma$ (a), granular (b), and lamellar B2 (c). $\bar{l}$ and $\bar{w}$ indicate the average spacing in axial and transverse direction, respectively. Aspect ratio $(\alpha)$ is defined as $\bar{l} / \bar{w}$. 


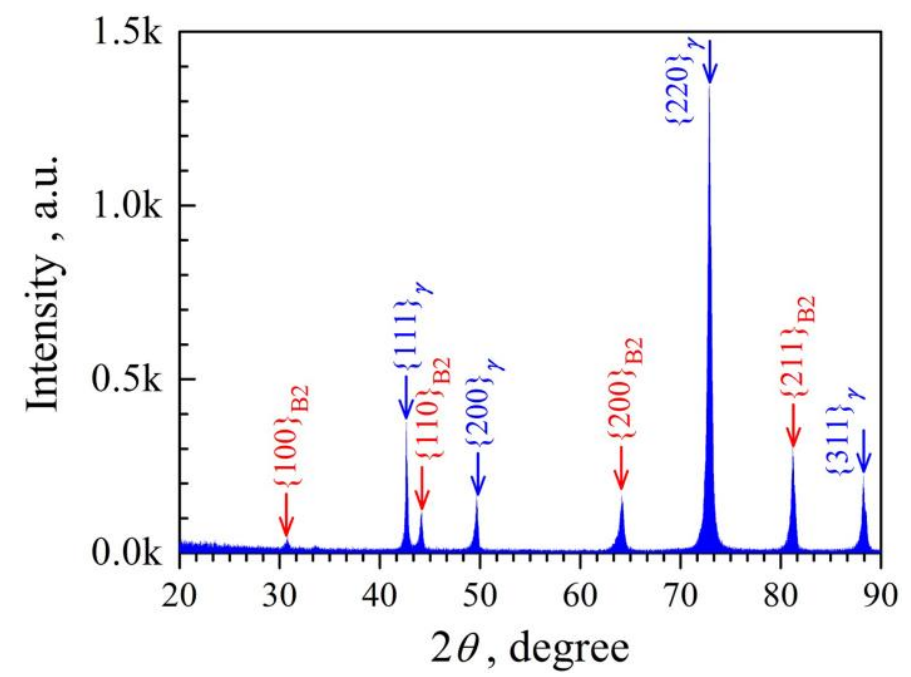

Figure 3 XRD spectra after cold rolling and annealing. 

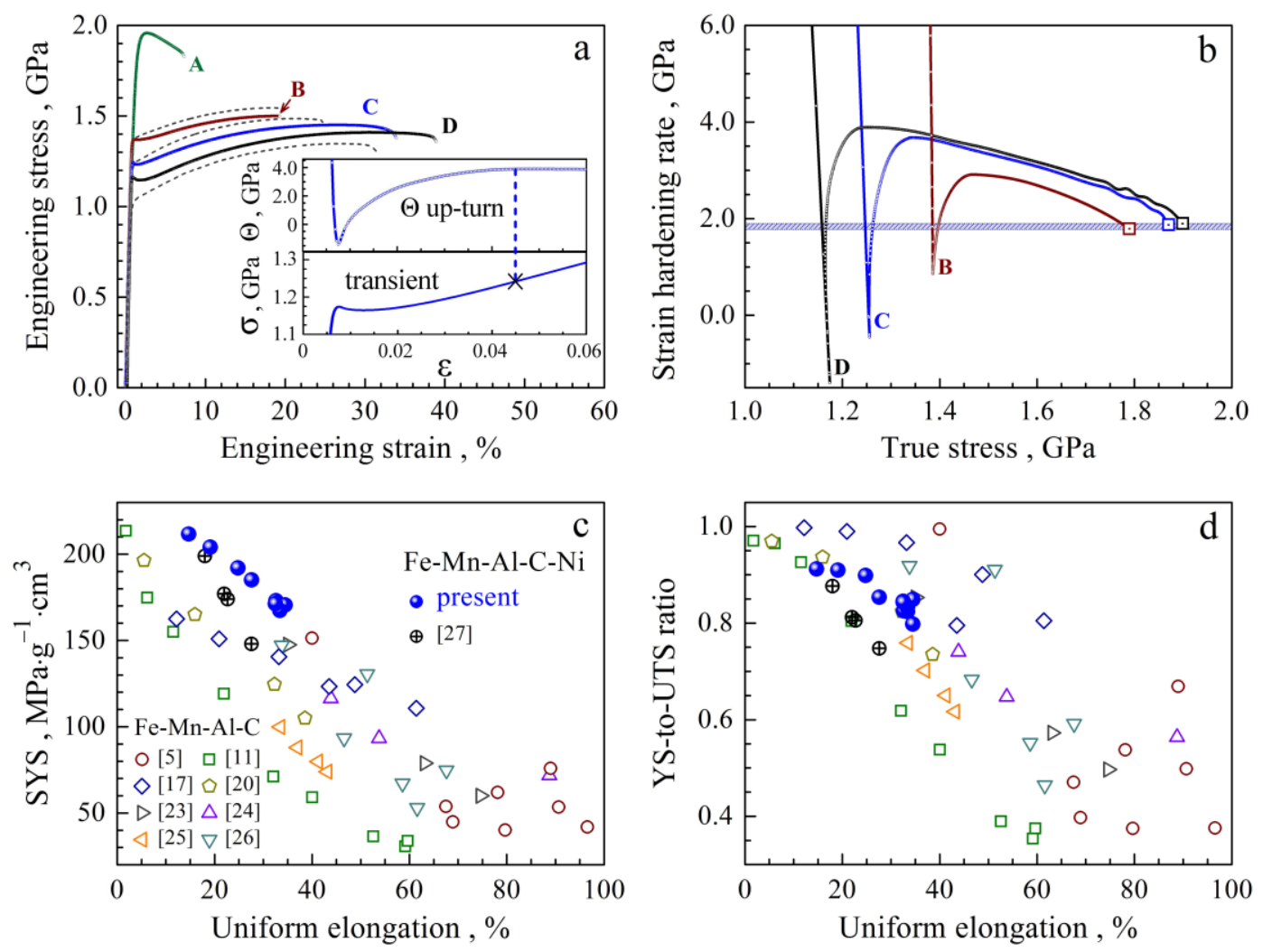

Figure 4 a. Tensile engineering stress-strain $(\sigma-\varepsilon)$ curves at a strain rate of $5 \times 10^{-4} \mathrm{~s}^{-1}$. A: cold rolling with strain $80 \%$, B and C: annealing at 800 and $900^{\circ} \mathrm{C}$ for $2 \mathrm{~min}, \mathrm{D}$ : annealing at $900^{\circ} \mathrm{C}$ for $15 \mathrm{~min}$. Inset shows a close-up of both true $\sigma-\varepsilon$ curve and strain hardening rate $(\Theta)$ vs true strain curve of sample D. Note that the $\Theta$ maximum corresponds to the inflection point marked by a ' $x$ '. b. $\Theta$ vs true stress curves. Square indicates the ultimate tensile strength. c. Specific yield strength (SYS, i.e. yield strength-to-mass density ratio) versus uniform elongation. d. Yield strength-to-ultimate tensile strength (YS-to-UTS) ratio versus uniform elongation. The present HSSS is compared with the Fe-Mn-Al-C-Ni based HSSS reported by Kim et al. (Ref. [27]) and the conventional Fe-Mn-Al-C based steels [5,11,17,20,23-36]. 

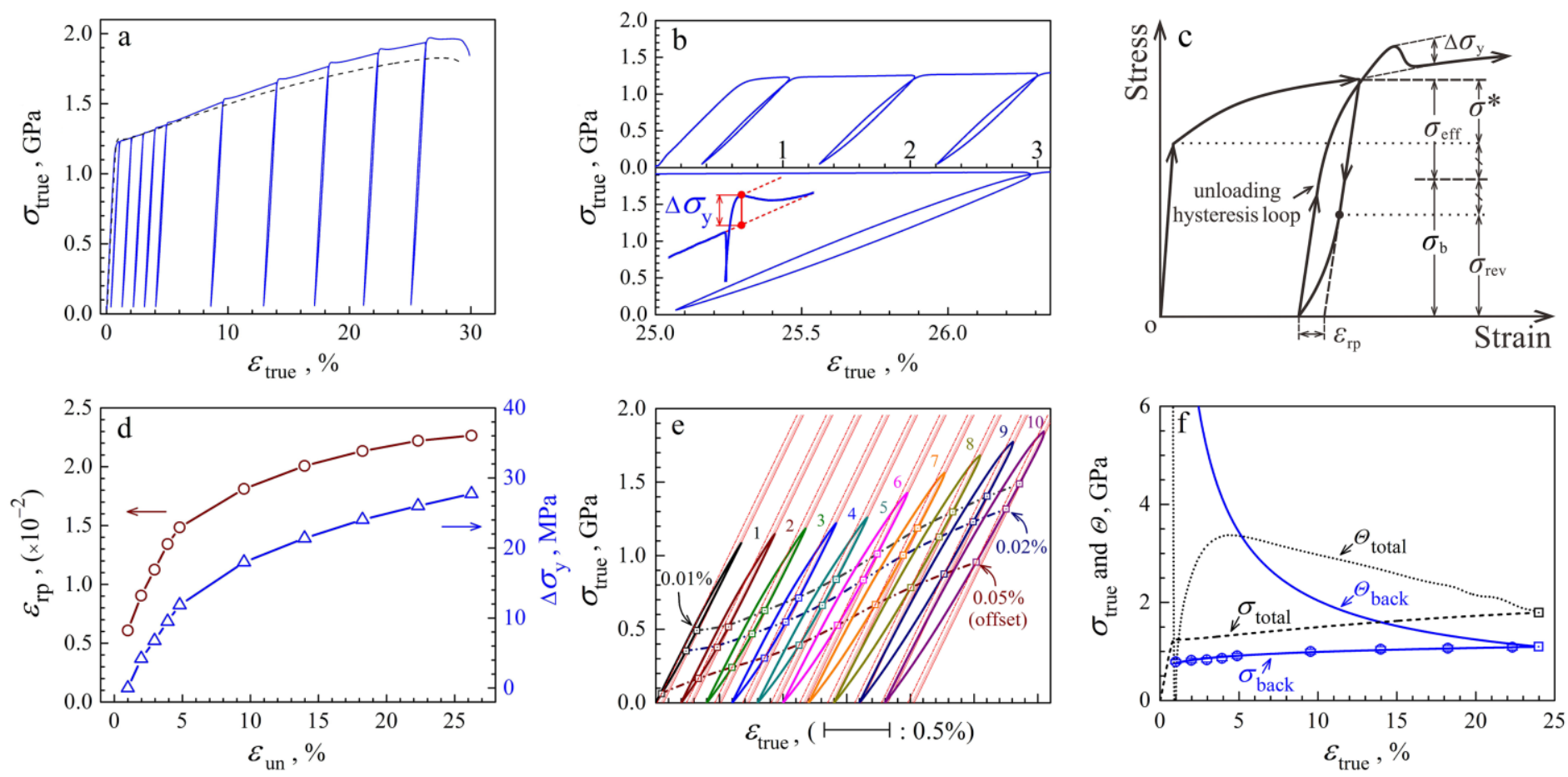

Figure 5 Back stress hardening. a. Tensile LUR true $\sigma-\varepsilon$ curve for sample D. The monotonic $\sigma-\varepsilon$ curve is also shown for comparison. b. Close-up of hysteresis loops of the first three in a (upper) and the last loop (lower). Inset shows the unloading yielding effect $\left(\Delta \sigma_{\mathrm{y}}\right)$. c. Schematic of two typical features in each unloading-reloading cycle, i.e. hysteresis loop and $\Delta \sigma_{y}$. d. Reverse plastic strain $\left(\varepsilon_{\mathrm{rp}}\right)$ and $\Delta \sigma_{\mathrm{y}}$ versus unloading strains $\left(\varepsilon_{\mathrm{un}}\right)$. e. Loop assembly showing the unloading yield stress $\left(\sigma_{\mathrm{un}}\right)$ marked by square by three strain offsets, namely $0.01 \%, 0.02 \%$, and $0.05 \%$. f. Back stress and hardening rate versus true strain. 

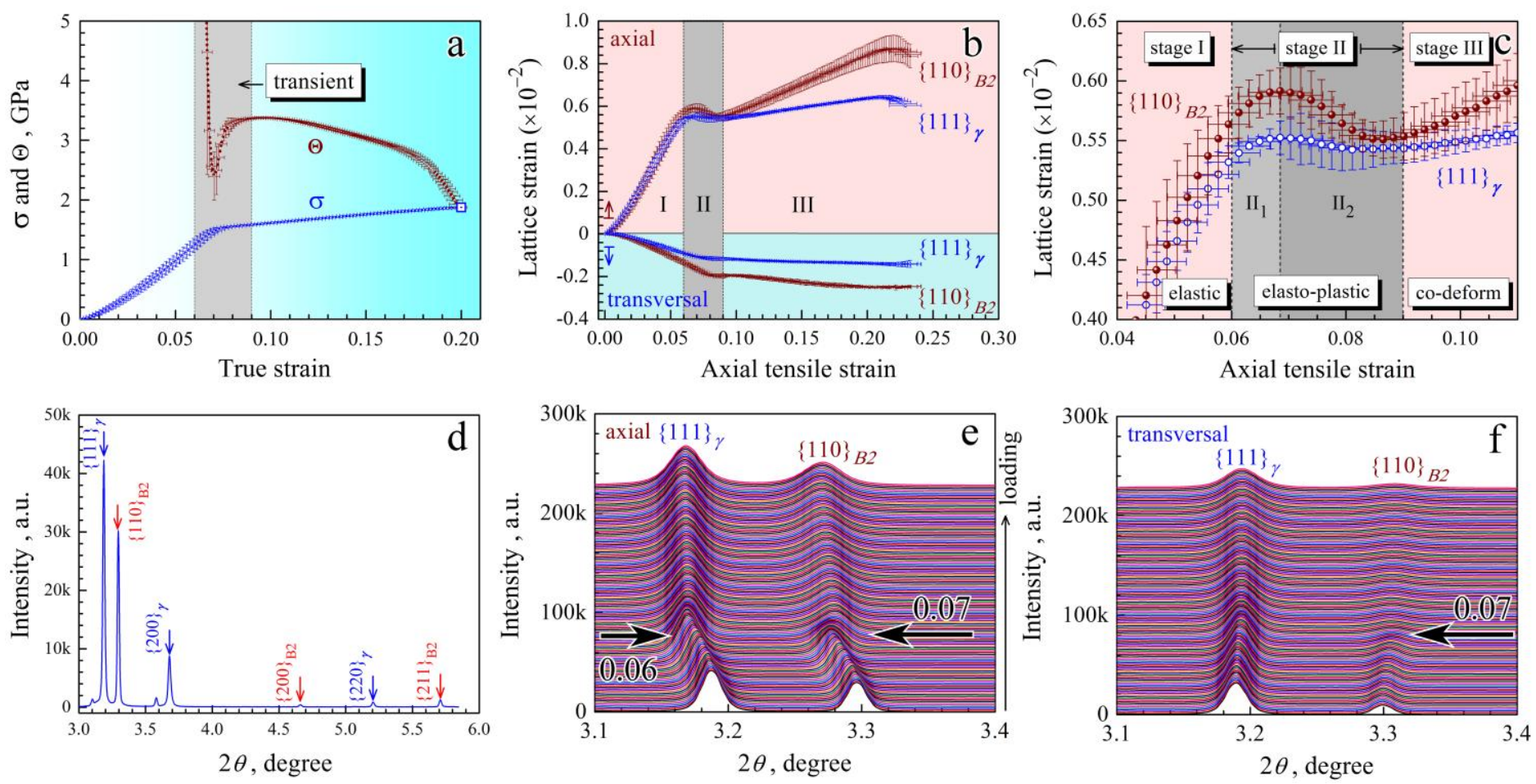

Figure 6 Stress and strain partitioning from in situ X-ray diffraction measurements. a. $\sigma-\varepsilon$ and $\Theta-\varepsilon$ curves. Note the $\Theta$ up-turn. b. Lattice strains in axial (loading) and transverse direction, respectively, in both $\gamma$ and B2 versus applied tensile strain. Note the three-stage evolution of lattice strains. c. Close-up of the three stages in $\mathrm{b}$ in axial direction. Also note stage II consists of $\mathrm{II}_{1}$ where $\gamma$ begins to yield while $\mathrm{B} 2$ stays elastic, and $\mathrm{II}_{2}$ where $\mathrm{B} 2$ starts to yield. d. High-energy X-ray diffraction spectra. e and f. Diffraction patterns in axial and transverse directions, respectively. The applied tensile strain increases from bottom to top. 

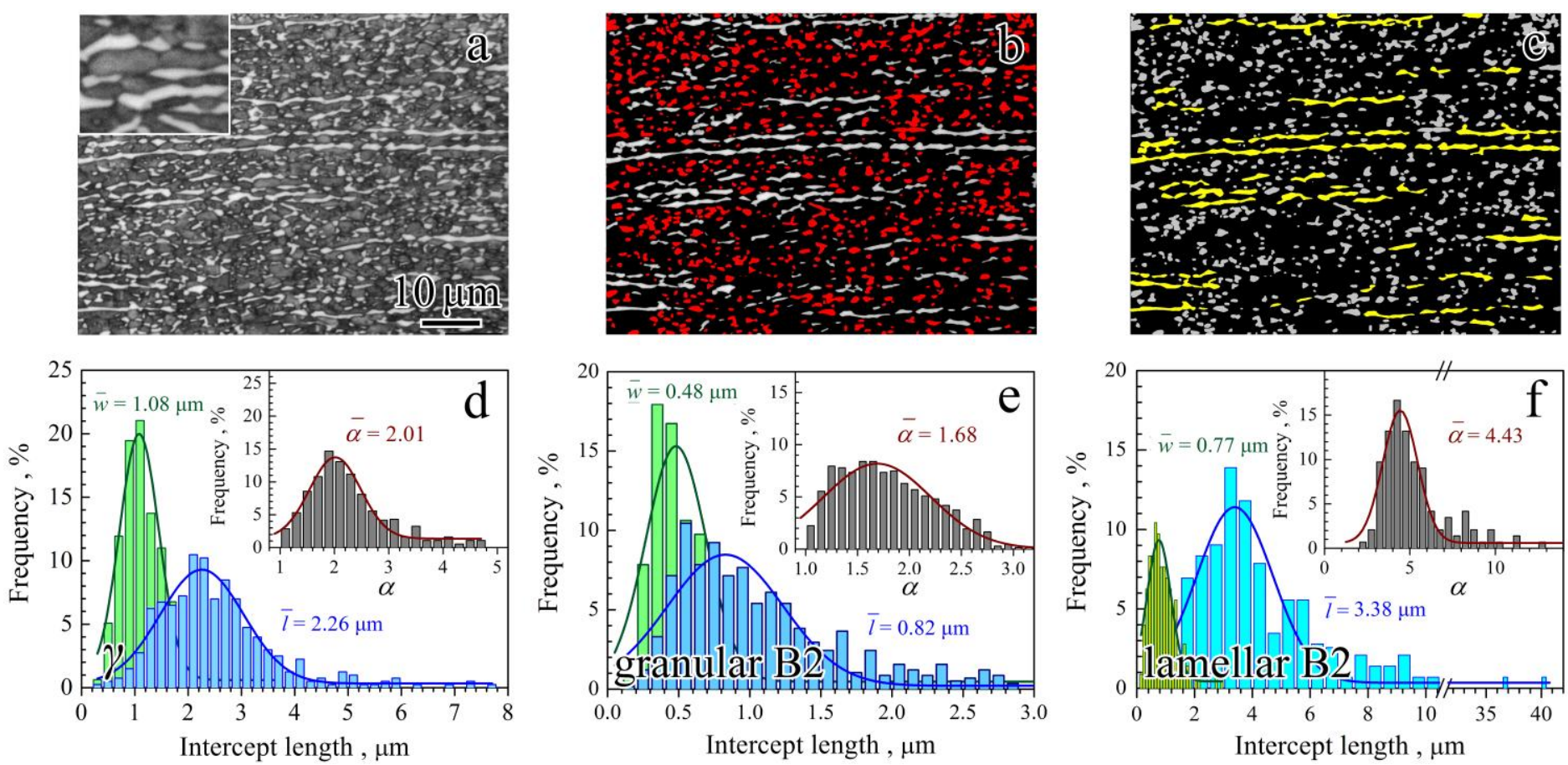

Figure 7 Aspect ratio measurements after tensile testing in sample D. a-c. SEM images after tensile tests in $\gamma$ (light-grey) and granular (red) and lamellar (yellow) B2. d-f. Corresponding histograms of aspect ratios. In b and c, the B2 particles and lamellae were colored, respectively, based on their morphology in the SEM images. 


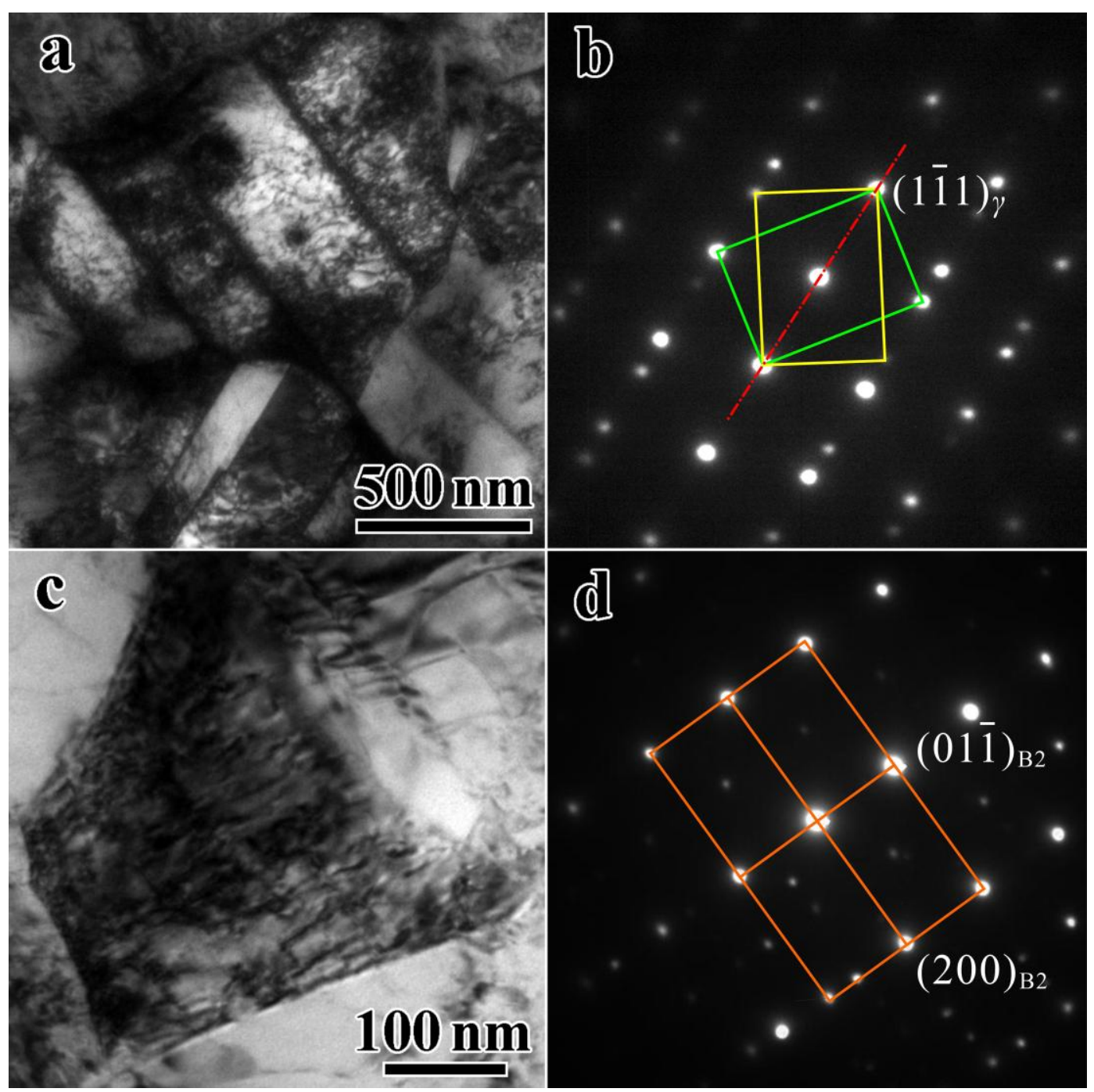

Figure 8 TEM micrographs showing high density of dislocations in both $\gamma$ (a) and B2 (c) grains at tensile strain of $\sim 26 \%$ in sample D. $b$ and d. Corresponding selected area diffraction patterns with $[011]_{\gamma}$ and $[011]_{\mathrm{B} 2}$ zone axes, respectively. 

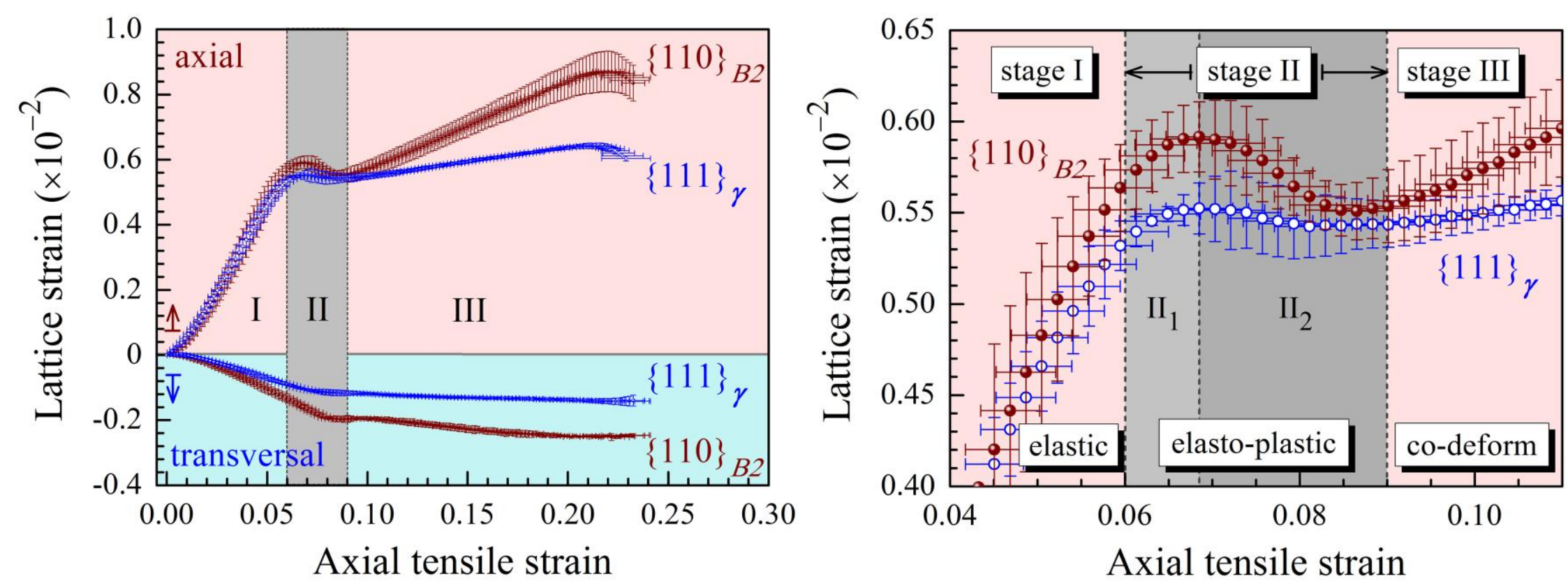